\title{
Effects of Plant Cultivating Activity for Reducing Parental Stress
}

\author{
Hye Sook Jang, Gyung Mee Gim, Sun-Jin Jeong*, and Jae Soon Kim \\ National Institute of Horticultural \& Herbal Science, RDA, Wanju-gun 56365, South Korea
}

\begin{abstract}
This study was conducted to find out the influence of plant cultivating activities program to reduce the stress of parents. Saliva cortisol salivettes system method was taken effect for this study with total 27 of parents who are $39.15 \pm 3.5$ years old on average and have children attending primary school. The cortisol level was measured once a week, total 10 times, before/after 90 minutes plant cultivating activities program. As the result of this program, the total cortisol decreased after the plant cultivating activities program and there was a statistically significant difference with the total cortisol $(\mathrm{t}=14.521, p<.01)$. In addition to this, the final session has the most effect on decreasing the stress compare to other previous sessions. As the result of asking 8 questions on a 7 point Likert scale about preference for plants and plant-related experiences before/after the plant cultivating activities program, the score difference of "The experiences of growing plants still have an influence on my life" was highest between before and after the program at a statistically significant difference. These results imply that the plant cultivation program can boost stress-reducing effects, allow parents being familiar with plants, and provide positive influence on relieving parenting stress. In addition to this, the standardization of physiological changes can be established more easily with the saliva cortisol method as it is less stressful to the subject and a more convenient test, that can be taken anytime and anywhere, compared to the blood cortisol method.
\end{abstract}

Keywords: blood cortisol, physiological, saliva cortisol

\section{Introduction}

As the word 'healing' has been highlighted in Korea recently, studies on methods to relieve stress caused in parent-child relationships have been conducted, and the results of studies conducted among patients with certain diseases and the effects of actual healing programs have been continuously reported. Out of various healing programs, plant cultivating activities give participants chances to experience the growth of plants and to express their emotions or recognize themselves by integrating the life cycle of plants and humans (Lee, 2009). In addition, it was reported that parents of elementary school students experienced that their depression and stress were relieved through plant cultivating activities, having positive effects on improvements in their relationships with children (Hwang et al., 2007). Parents today have been under a great deal of stress due to confusion and anxiety about whether they play their role well as a parent in this

This study was supported by the research project of the National Institute of Horticultural and Herbal Science, Rural Development Administration (PJ011376042017).

This study was supported by the Post-Doctoral Course Program of the National Institute of Horticultural and Herbal Science, Rural Development Administration (PJ011376042017).

Received: May 21, 2018, Revised: June 17, 2018, Accepted: June 18, 2018

First author: Hye Sook Jang, E-mail: jhs915@korea.kr, ORCID: 0000-0003-3011-8694

*Corresponding author: Sun-Jin Jeong, E-mail: sunjin75@korea.kr, ORCID: 0000-0001-6279-9733 
rapidly changing environment (Kim, 2005). Stress from child rearing is an emotional factor with the highest impact on stress that mothers experience in daily life (Han and Park, 1996). The biggest difficulty the parents face in the process of raising their children is not being able to control their anger due to instantaneous stress, which in turn aggravates conflicts with their children (Kim, 2007). For this reason, demand for education programs for parents to obtain skills for effectively controlling their emotions and anger in stress-driven conflicts with their children (Ko, 2009) and objective indicators for assessing their effects have grown recently.

Stress that people often experience in daily life is an anxious and threatening emotion that people face in difficult situations that they cannot handle emotionally or physically (Lazaru, 1993). When stress lasts for a long time and becomes chronic, the sympathetic nerves become dominant and stress hormones such as adrenaline and cortisol are excessively secreted, which reduces the level of immunity or increases the risk of numerous diseases (Kim et al., 2008). The level of cortisol can be measured using various methods such as analyzing serum, urine and saliva (Knaus et al., 2007). In addition, the level of cortisol in saliva are more stable and reflects its function better for a long time than that in blood, and thus it doest not require any additional treatment for saliva testing until analysis (Gordon et al., 2005). The collection of saliva is not invasive unlike the collection of blood and thus causes less stress to subjects without limitations such as location and time (Raff et al., 1998). In particular, cortisol in saliva is one of the most common stress hormones, and the level of cortisol is used as a reliable indicator for the level of stress that humans experience (Sreebny, 2000) and the activity of the endocrine system (Hellhammer et al., 2009).

Against this backdrop, various programs of plant cultivating activities were formed and provided for parents who are under stress from child rearing. In addition, this study aimed to assess and verify the effects of healing programs using plant cultivating activities on the relief of stress from child rearing by measuring the level of cortisol in saliva, an objective stress indicator.

\section{Methods}

\section{Selection of subjects}

In order to examine the effects of plant cultivating activities on the relief of stress that parents of students experience, their saliva was collected and the level of cortisol was analyzed. Subjects were selected among parents of students of an elementary school located in Jeonju, Korea. The purpose and methods of this study were fully explained to 27 female parents (average age: $39.15 \pm 3.5$ years), and this experiment was performed among those who signed a voluntary participation agreement. The subjects were instructed not to drink two days before this experiment, and not to eat food or drinks beverages that can stimulate saliva such as coffee, green tea and caffeine two hours before this experiment. This study was approved by the Institutional Review Board (e-IRB) of Chonbuk National University Hospital.

\section{Laboratory environmental conditions and plant cultivating activities for 1-10 sessions}

The saliva of subjects was collected two times before and after performing the program of plant cultivating activities in an indoor space in an elementary school located in Jeonju, Korea. The program was provided once a week, a total of 10 sessions (Table 1) in outdoor and indoor spaces in front of the cafeteria of the elementary school between 10AM to 12PM. The laboratory (length: $12.0 \mathrm{~m}$, width: $7.0 \mathrm{~m}$, height: $2.6 \mathrm{~m}$ ) was surrounded by light gray walls, and the intensity of illumination at the height of a table was $700 \pm 10 \mathrm{lux}$ (UT383 Mini Light Meters, Japan) and the temperature was $25 \pm 0.5^{\circ} \mathrm{C}$ 
Table 1. Plant cultivating activities completed by subjects

\begin{tabular}{cl}
\hline Session & \multicolumn{1}{c}{ Plant cultivating activities program } \\
\hline 1 & Orientation, learning the types of vegetable and cultivation methods, sowing vegetable seeds \\
2 & Placing vegetable name tags and planting seedlings \\
3 & Placing plant supports for pepper and tomato plants \\
4 & Learning natural enemies of crop pests and making natural pest deterrent with egg yolk oil and egg shell calcium \\
5 & Composing food waste with earthworms to make organic fertilizer \\
6 & Harvesting leafy vegetable and making Bibimbap \\
7 & Creating art with natural food coloring and learning health benefits of each color \\
8 & Harvesting herbs and creating pressed flower cards \\
9 & Learning hydroculture system for potato and sweet potato using hydro culture soil \\
10 & Harvesting crops and having a garden party \\
\hline
\end{tabular}

on average.

The program composed of plant cultivating activities was provided once a week, a total of 10 sessions by the following professional and assistant instructors: one main professional instructor (horticultural therapist registered - grade II certified by the Korean Horticultural Therapy Association; social worker certified by the Ministry of Health and Welfare; care worker in Jeollabuk-do; nursing assistance in Jeollabuk-do; craftsman floral design), one main assistant instructor (horticultural therapist registered for wellbeing certified by the Korean Horticultural Therapy Association; craftsman floral design certified by the Human Resources Development Service of Korea), and four assistant instructors who majored in horticulture, forestry and family science. Plant cultivating activities performed in this study include sowing seeds and planting seedlings using individual plant gardening boxes, making natural nutritional supplements and pesticides, etc.

In the first session, information on the overall direction for the program and materials used in the program was provided. Education on the species and characteristics of leafy vegetables and the types of plants to be planted and the methods of planting was provided by utilizing audiovisual materials. After that, the composition of plants for gardening boxes was designed, and the soil for gardens was mixed. Seeds were also sowed. In the second session, seedlings of plants such as red lettuce, green lettuce, chili pepper, tomato, lavender, rosemary, Catharanthus roseus, etc. were planted, and signs were decorated. In the third session, sowed plants were transplanted, and the extra sprouts of chili pepper and tomato plants were removed. In addition, plants that need rods were identified, and subjects were informed of methods to properly place rods for chili pepper and tomato and places rods following the instructions. In the fourth session, subjects studied insects and natural enemies in gardens, and made and used egg yolk oil, an eco-friendly pesticide and eggshell calcium, a natural nutritional supplement for garden boxes to easily prevent diseases and insect pests. In the fifth session, eco-friendly compost was made using thinned-out leaves and food waste and earthworms for the next session.

In the sixth session, the extra sprouts of fruit vegetable plants such as chili pepper and tomato were removed and they were additionally tied with rods. Leafy vegetables that were grown in the previous sessions were harvested to make and share bibimbap, a mixed rice, with other participants. In the seventh session, plants that were grown in garden boxes were thinned out, and weeds were removed. Vegetables were collected to make color-food artworks. Using the collected 
and prepared vegetables, color-food artworks were created and in the process information on the nutritions of each color of vegetables and fruits, ways to eat them and their efficacy was provided for subjects. In the eighth session, herbs that were grown in gardening boxes were collected and pressed to make letter paper. In the ninth session, subjects were informed of ways to aquaculture root vegetables indoor by utilizing hydro culture soil and ways to maintain them based on their characteristics, and planted them. In the tenth session, plants that subjects had grown in gardening boxes so far such as leafy lettuce, herbs, tomato and chili pepper were harvested and shared with other participants, and the advantages and disadvantages of plant cultivating activities using gardening boxes and their feelings were shared together.

\section{Materials and methods}

Plant cultivating activities performed in this study include those growing vegetables and flowering plants indoor such as sowing seeds and harvesting them outdoor using individual plant cultivating boxes $(100 \times 60 \times 45 \mathrm{~cm}, 10$ horticultural species), and those expressing themselves using collected vegetables and plants. The program was performed once a week, 90 minutes per session. The saliva of subjects was collected before and after each session of the program. Since the level of cortisol in the case of adults is the highest early in the morning, and the lowest between 8PM to 2AM on the next day (Posener et al., 2000), the saliva of subjects was collected at the same times before and after each of the 10 sessions (before: 10AM, after: 11:30AM) (Choi et al., 2014). Saliva was collected using a saliva collection kit equipped with a cotton swab. In order to minimize the risk of contamination of the saliva collection swab caused by any contact with hands or air, saliva was collected by accurately and strictly following the standardized procedures.
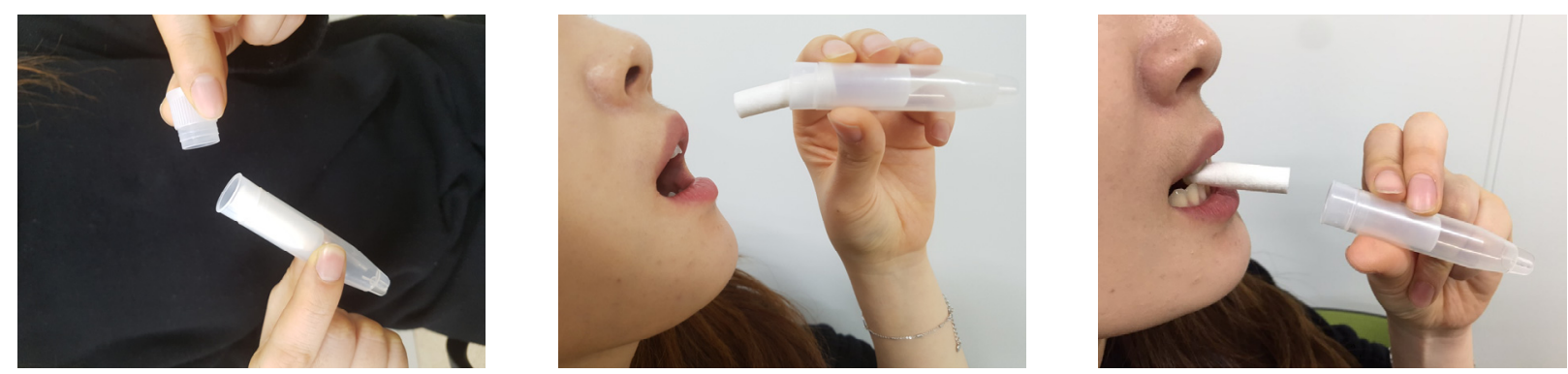

Figure 1. The sequential steps in saliva collection using Salivette system.

\section{Methods to collect and analyze saliva using a Salivette collection kit}

The saliva of subjects was collected according to the following procedures: First, lift the lid off the tube and expose the cotton swab inside the tube to the mouth of the tube. Second, tilt the tube and fall the cotton swab directly into the mouth without touching it with the hands. Third, chew it very gently for 5 minutes in the mouth and place it back into the tube without touching it with the hands. Fourth, close the lid tightly, and record the code number of the subject and the date of collection. Fifth, put the collected saliva into a portable cooler filled with dry ice and move it to a freezer for storage (Schwartz et al., 1998). Sixth, analyze cortisol in the collected saliva using an ER HS SALIVARY CORTISOL kit (Salimetrics Inc. USA) and a VERSA Max Microplate Reader (Molecular device, USA). The unit of analysis was $\mu \mathrm{g} / \mathrm{dL}$. The higher the level of cortisol in saliva, the higher the level of stress reactions, and the lower the level of cortisol in saliva, the lower the level of stress reactions. 


\section{Survey on subjects' preference for plants and plant-related events}

A questionnaire to survey subjects' preference for plants and plant-related events was composed of 8 questions, and the questions were revised and supplemented through experts' review (one with a doctoral degree of agricultural education, three with a doctoral degree of horticulture, one with doctoral degrees of horticulture and horticultural therapy, one with a doctoral degree of psychology). The questionnaire was composed of questions to examine subjects' preference for plants and memories related to plants before performing plant cultivating activities. In addition, in order to improve the reliability and public confidence of the questions, they were reviewed by experts to adjust and those that were verified through reliability analysis were used only. Four questions from A to D were about subjects' preference for plants, and the rest four questions from $\mathrm{E}$ to $\mathrm{H}$ were about their plant-related events as follows: Question A:"I like every plant unconditionally"; Question B: "I have many plants at my house"; Question C: "I usually have a lot of interest in plants around me"; Question D: "I often buy plants at flower shops (flower gardens, farms, etc.)"; Question E: "Whenever I find my favorite plants, that makes me feel better"; Question F: "Whenever I think of my favorite plants, that evokes related memories"; Question G: "The reasons and motivations that made me like plants still have an influence on my life"; and Question H: "The experiences of raising plants still have an influence on my life." A 7-point Likert scale (1 point: strongly disagree, 7 points: strongly agree) was used to score each question.

\section{Statistical analysis}

Statistical analysis was performed using IBM SPSS ver. 25.0 in this study. The reliability of the measurement tool was analyzed by calculating Cronbach's $\alpha$. The level of cortisol in saliva and subjects' preference for plants and plant-related events were analyzed using a paired sample t-test, and correlations between subjects' preference for plants and plantnrelated events were compared using Pearson's correlation analysis.

\section{Results and Discussion}

\section{General characteristics}

The average age of 27 female parents surveyed in this study was $39.15 \pm 3.5$ years. The share of those in their $30 \mathrm{~s}$ and 40 s was $57.7 \%$ and $42.3 \%$ respectively, and the share of those who are full-time housewives was $66.7 \%$, followed by those who work in a professional field (14.8\%), those who are self-employed (7.4\%), others (7.4\%), and those who work in service industries (3.7\%). The share of those who graduated from graduate school, 4-year college, 2-year college and high school was $3.7 \%, 40.7 \%, 33.3 \%$ and $22.2 \%$ respectively. Those whose average monthly household income is over 4 million won accounted for $66.7 \%$, followed by 3.01-4 million won (22.2\%), 2.51-3 million won (7.4\%), and 1.01-1.5 million won (3.7\%) (data not shown).

\section{Changes in the level of cortisol of subjects after participating in plant cultivating activities}

Changes in the level of cortisol before and after performing plant cultivating activities in each session (a total of 10 sessions) were analyzed, and it was found that the level of cortisol throughout the entire sessions decreased after participating in the program of plant cultivating activities compared to the level before participating in the program. There was a statistically significant difference in the average level of cortisol between before and after participating in the program - down by $0.104 \mathrm{ug} / \mathrm{dL}$ from $0.184 \mathrm{ug} / \mathrm{dL}$ to $0.104 \mathrm{ug} / \mathrm{dL}(\mathrm{t}=14.521, p<.01)$ (Table 2$)$. In addition, the level of 
Table 2. The changes in stress (cortisol) after 10 sessions of plant cultivating activities

\begin{tabular}{ccccc}
\hline & \multicolumn{2}{c}{ Saliva cortisol value $(\mathrm{ug} / \mathrm{dL})$} & $\mathrm{t}$ & $p$ \\
\cline { 2 - 4 } & Pre & Post & & \\
\hline Total & $0.184 \pm 0.09^{\mathrm{z}}$ & $0.104 \pm 0.06$ & 14.521 & $0.002^{* *}$ \\
\hline
\end{tabular}

${ }^{\mathrm{z}}$ Values are mean \pm standard deviation $(\mathrm{n}=210)$.

${ }^{* *}$ Significant at $p<.01$ by paired t-test $(\mathrm{n}=210)$.

Table 3. The changes in stress (cortisol) after each session of plant cultivating activities

\begin{tabular}{|c|c|c|c|c|c|c|}
\hline \multirow{2}{*}{ Session } & \multicolumn{2}{|c|}{ Saliva cortisol value (ug/dL) } & \multirow{2}{*}{$\mathrm{n}$} & \multirow{2}{*}{ Pre-Post } & \multirow{2}{*}{$\mathrm{t}$} & \multirow{2}{*}{$p$} \\
\hline & Pre & Post & & & & \\
\hline 1 & $0.190 \pm 0.08^{z}$ & $0.107 \pm 0.06$ & 23 & 0.083 & 7.454 & $0.000^{* * *}$ \\
\hline 2 & $0.224 \pm 0.12$ & $0.128 \pm 0.08$ & 23 & 0.096 & 7.455 & $0.000^{* * *}$ \\
\hline 3 & $0.185 \pm 0.11$ & $0.097 \pm 0.05$ & 24 & 0.088 & 5.315 & $0.000^{* * *}$ \\
\hline 4 & $0.159 \pm 0.07$ & $0.065 \pm 0.02$ & 22 & 0.094 & 7.065 & $0.000^{* * *}$ \\
\hline 5 & $0.168 \pm 0.06$ & $0.115 \pm 0.06$ & 22 & 0.053 & 3.597 & $0.002^{* *}$ \\
\hline 6 & $0.217 \pm 0.14$ & $0.149 \pm 0.08$ & 20 & 0.068 & 2.221 & $0.039^{*}$ \\
\hline 7 & $0.168 \pm 0.08$ & $0.101 \pm 0.07$ & 22 & 0.067 & 2.918 & $0.008^{* *}$ \\
\hline 8 & $0.176 \pm 0.05$ & $0.115 \pm 0.04$ & 20 & 0.061 & 5.414 & $0.000^{* * *}$ \\
\hline 9 & $0.188 \pm 0.08$ & $0.099 \pm 0.03$ & 17 & 0.089 & 5.274 & $0.000^{* * *}$ \\
\hline 10 & $0.162 \pm 0.07$ & $0.054 \pm 0.04$ & 17 & 0.108 & 6.319 & $0.000^{* * * *}$ \\
\hline
\end{tabular}

${ }^{\mathrm{z}}$ Values are mean \pm standard deviation $(\mathrm{n}=210)$.

${ }^{*, * *, * * *}$ Significant at $p<.05, .01$ and .001 , respectively, by paired t-test $(\mathrm{n}=210)$.

cortisol after the last session (10th session) was the lowest compared to the level before participating in the program, indicating that plant cultivating activities are effective in reducing stress (Table 3 ). These results are supported by those of Kwak (2004), Lee (2006) and Ulrich (1981) that plant cultivating activities in artificial spaces or activities that utilize natural materials have not only environmental effects but also emotional effects such as psychological stability, serenity and stress relief. In addition, these results are similar to those of other studies such as Jang et al. (2017) and Lee et al. (2013). Jang et al. (2017) found plant decorating activities were more effective in improving the physiological and psychological stability and relaxation of workers than document writing activities. Lee et al. (2013) was conducted among prisoners to be released and it was found that the level of cortisol in the saliva and depression of the experimental group statistically significantly decreased after participating in horticultural activities while there was no statistically significant change in the control group.

\section{Changes in subjects' preference for plants and plant-related events after participating in plant cultivating activities}

A paired t-test was performed to examine changes in subjects' preference for plants and plant-related events after participating in the entire program of plant cultivating activities, and the score of "Question $\mathrm{H}$ : The experiences of raising plants still have an influence on my life" statistically significantly increased after participating in the program. In addition, 
Table 4. The changes in preference for plants and plant-related events before/after the plant cultivating activities

\begin{tabular}{|c|c|c|c|c|c|}
\hline \multirow{2}{*}{ No. } & \multicolumn{2}{|c|}{ Plant cultivating activity } & \multirow{2}{*}{$\mathrm{t}$} & \multirow{2}{*}{$p$} & \multirow{2}{*}{ Cronbach's c } \\
\hline & Pre & Post & & & \\
\hline \multicolumn{6}{|c|}{ Preference for plants } \\
\hline $\mathrm{A}^{\mathrm{y}}$ & $4.33 \pm 1.66^{\mathrm{z}}$ & $4.37 \pm 1.60$ & -0.214 & $0.832^{\mathrm{NS}}$ & 0.853 \\
\hline $\mathrm{B}$ & $3.26 \pm 1.46$ & $3.52 \pm 1.63$ & -1.427 & $0.166^{\mathrm{NS}}$ & 0.903 \\
\hline $\mathrm{C}$ & $4.04 \pm 1.80$ & $4.19 \pm 1.52$ & -0.811 & $0.425^{\mathrm{NS}}$ & 0.834 \\
\hline $\mathrm{D}$ & $3.04 \pm 1.63$ & $3.04 \pm 1.56$ & 0.000 & $1.000^{\mathrm{NS}}$ & 0.861 \\
\hline \multicolumn{6}{|c|}{ Plant-related events } \\
\hline $\mathrm{E}$ & $4.96 \pm 1.43$ & $4.70 \pm 1.61$ & 1.158 & $0.257^{\mathrm{NS}}$ & 0.791 \\
\hline $\mathrm{F}$ & $3.74 \pm 1.99$ & $3.74 \pm 1.79$ & 0.000 & $1.000^{\mathrm{NS}}$ & 0.764 \\
\hline G & $2.96 \pm 1.70$ & $3.48 \pm 1.67$ & -1.929 & $0.065^{\mathrm{NS}}$ & 0.841 \\
\hline $\mathrm{H}$ & $3.04 \pm 1.83$ & $4.00 \pm 1.75$ & -2.987 & $0.006^{* *}$ & 0.726 \\
\hline
\end{tabular}

Note. 7-point Likert scale was used where $1=$ strongly disagree; $7=$ strongly agree.

${ }^{\mathrm{z}}$ Values are mean \pm standard deviation $(\mathrm{n}=54)$.

${ }^{\mathrm{y}} \mathrm{A}=\mathrm{I}$ like every plant unconditionally.; $\mathrm{B}=\mathrm{I}$ have many plants at my house.; $\mathrm{C}=\mathrm{I}$ usually have a lot of interest in plants around me.; $\mathrm{D}=\mathrm{I}$ often buy plants at flower shops.; $\mathrm{E}=$ Whenever I find my favorite plants, that makes me feel better.; $\mathrm{F}=$ Whenever I think of my favorite plants, that evokes related memories.; $\mathrm{G}=$ The reasons and motivations that made me like plants still have an influence on my life.; $\mathrm{H}=$ The experiences of raising plant still have an influence on my life.

${ }^{* * * *}$ Significant at $p<.05$ and .01 , respectively, by paired t-test. ${ }^{\text {NS }}$ non-significant.

three questions about preference for plants and the rest two questions about plant-related events did not show any statistically significant change, but still increased. The results of this study that participating in plant-related activities in person has positive effects were similar to the results of an earlier study that the score of the question "I am willing to invest in the purchase of plants" among questions about loyalty statistically significantly increased after experiencing activities of creating an indoor garden. The value of Cronbach's $\alpha$ of a total of 8 questions, 4 questions each about preference for plants and plant-related events, ranged between 0.726 and 0.903 , indicating high internal reliability (Table 4).

\section{Conclusions}

In this study, the level of cortisol in the saliva of a total of 27 parents (average age: $39.15 \pm 3.5$ years) who have elementary school children was measured using a Salivette collection kit in order to examine the effects of plant cultivating activities on the reduction of their stress level. The program of plant cultivating activities designed in this study was performed once a week, a total of 10 sessions for 90 minutes per session and the level of cortisol was measured before and after each session. Changes in the level of cortisol before and after participating in plant cultivating activities were compared, and the level of cortisol after each session decreased, and the total level of cortisol after participating in the program statistically significantly decreased $(\mathrm{t}=14.521, p<.01)$. In addition, the level of cortisol after the last session (10th session) was the lowest compared to the level after other sessions, indicating that plant cultivating activities are effective in relieving stress. Subjects were instructed to score each of the 8 questions about preference for plants and plant-related events using a 7-point Likert scale before and after participating in the program of plant cultivating activities, and the score of "Question H: The experiences of raising plants still have an influence on my life" statistically 
significantly increased after participating in the program. These results indicate that the program of plant cultivating activities reduced the level of stress of parents who participated in the program, and that plant cultivating experiences gave them chances to be around plants and had a positive impact on the therapeutic effects of activities utilizing plants. In addition, it will be possible to standardize physiological changes by continuously conducting studies on ways to measure the level of cortisol in saliva that cause less stress to subjects without limitations such as location and time.

\section{References}

Choi, S.H., I.S. See, I.J. Song, O.J. Kwon, K.O. Park, H.J. Hong, K.K. Sung, and S.K. Lee. 2014. Method of saliva collection for salivary cortisol measurement. Korean J. Orient. Physiol. Pathol. 28(2):223-232. DOI:10.15188/kjopp. 2014.04.28.2.223

Gordon, M.K., E. Peloso, A. Auker, and M. Dozier. 2005. Effect of flavored beverage crystals on salivary cortisol enzyme-immunoreactive assay measurements. Dev. Psychobiol. 47:189-195. DOI:10.1002/dev.20081

Han, S.Y. and S.Y. Park. 1996. Mother's parenting stress and the goodness / Poorness - of - fit with temperament. Korean J. Child Stud. 17(1):245-258.

Hellhammer, D.H., S. Wüst, and B.M. Kudielka. 2009. Salivary cortisol as a biomarker in stress research. Psychoneuroendocrinology 34(2):163-171. DOI:10.1016/j.psyneuen.2008.10.026

Hwang, H.J., Y.A. Lee, J.E. Song, and K.C. Son. 2007. Effect of horticultural therapy based upon reality therapy on the reduction of depression, the change in parental sense of competence, and stress coping types of elementary student's mother. Korean J. Hortic. Sci. Technol. 25(3):268-276.

Jang, H.S., G.M. Gim, K.J. Kim, and H.H. Jung. 2017. Change of physiology and emotion according to plant -decoration activity in workers. J. People Plants Environ. 20(5):555-566. DOI:10.11628/ksppe.2017.20.5.555

Jang, H.S., K.J. Kim, E.H. Yoo, and H.H. Jung. 2016. Impact of indoor-garden in the public building of lounge to the psychological effect of resident. J. Korean Soc. People Plants Environ. 19(3):167-174. DOI: 10.11628/ksppe.2016. 19.3.167

Kim, J.N. 2005. The effectiveness of the counseling-utilized parent education for mothers (CUPEM). Doctoral dissertation, Yonsei University, Seoul, Korea.

Kim. K.T., J.M. Kim, J.H. Kim, K.W. Song, S.H. Oh, Y.D. Yoon, H.S. Yoon, C.J. Lee, B.N. Cho, and E.G. Hong. 2008. Endocrinology (6th ed.). Seoul, Korea: Bioscience.

Kim, Y.J. 2007. Development of an anger control parenting program and verification of its effects. Master's thesis, Chonnam National University, Gwangju, Korea.

Knaus, J., R. Wiese, and U. Janßen. 2007. The processing of word stress: EEG studies on task-related components. ICPhS XVI 709-712. Retrieved from http://www.icphs2007.de/conference/Papers/1209/1209.pdf

Ko, N.H. 2009. Effects of transactional analysis-utilized parent education program on mother-child communication, parenting efficacy and parenting stress. Master's thesis, Yonsei University, Seoul, Korea.

Kwak, S.O. 2004. A study on the environmental marketing for interior scape within apartment. Doctoral dissertation, Sangmyung University, Cheonan, Korea.

Lazarus, R.S. 1993. From psychological stress to the emotions: A history of changing outlooks. Annu. Rev. Psychol. 44:1-21. DOI:10.1146/annurev.ps.44.020193.000245

Lee, G.G. 2006. Visual preference in green roof sites. J. Korean Inst. Landsc. Archit. 34(5):32-38.

Lee, M.J. 2009. The effect of the application of horticultural therapy by programs on the vocational rehabilitation, heart rate variability, and cortisol of the intellectual disabilities. Master's thesis, Catholic University, Daegu, Korea.

Lee, S.M., J.H. Moon, S.J. Jeong, and Y.J. Lee. 2013. Effects of horticultural therapy program focusing on cultivating activities for prisoners scheduled to be released on depression and salivary cortisol. J. Korean Soc. People Plants 
Environ. 16(4):173-180. DOI:10.11628/ksppe.2013.16.4.173

Posener, J.A., C. DeBattista, G.H. Williams, H.C. Kraemer, B.M. Kalehzan, and A.F. Schatzberg. 2000. 24-hour monitoring of cortisol and corticotropin secretion in psychotic and nonpsychotic major depression. Arch. Gen. Psychiatry 57(8): 755-760.

Raff, H., J.L. Raff, and J.W. Findling. 1998. Late-night salivary cortisol as a screening test for Cushing's syndrome. J. Clin. Endocrinolo. Metabol. 83(8):2681-2686.

Schwartz, E.B., D.A. Granger, E.J. Susman, M.R. Gunnar, and B. Laird. 1998. Assessing salivary cortisol in studies of child development. Child Dev. 69(6):1503-1513.

Sreebny, L.M. 2000. Saliva in health and disease: an appraisal and update. Int. Dent. J. 50(3):140-161.

Ulrich, R.S. 1981. Natural versus urban scenes: Some psychophysiological effects. Environ. Behav. 13(5):523-556. DOI:10.1177/0013916581135001 